\title{
ANALISA KOLEKTOR SURYA TIPE PELAT DATAR MENGGUNAKAN PIPA KALOR SEBAGAI PENGAMBIL PANAS PADA PENYERAP(ABSORBER)
}

\author{
Oleh : \\ Nugroho Gama Yoga \\ Jurusan Teknik Mesin, Fakultas Teknik, Universitas Negeri Jakarta \\ Jln. Rawamangun Muka, Jakarta Timur
}

\begin{abstract}
ABSTRAK
Pemanfaatan potensial energi matahari yang kekal dan melimpah belum banyak diterapkan.Sumber energi ini mudah diperoleh terutama di daerah katulistiwa, dan pemanfaatannya ramah lingkungan. Salah satu alat pengambilenergi matahari dalam bentuk energi termal adalah kolektor surya. Penggunaan pipa kalor yang dapat merespon dengan cepat adanya panas yang datang dalam waktu singkat. Kolektor surya dengan luas penyerap 120 × $200 \mathrm{~cm}$ dan menggunakan pipa kalor berdiameter $1,78 \mathrm{~cm}$ sepanjang $128 \mathrm{~cm}$ sebagai pengambil panas dari absorber ke aliran air. Dalam penelitian ini akan diukur temperatur kolektor, air masuk dan keluar pengambil panas, serta energi yang berhasil diperoleh.
\end{abstract}

Kata kunci : kolektor surya, pipa kalor.

\section{Pendahuluan}

Ketersediaan energi matahari yang melimpah dan kekal sangat potensial untuk dikembangkan. Kelebihan lain yaitu ramah lingkungan karena tidak menimbulkan polusi. Untuk memanfaatan energi ini diperlukan suatu alat, salah satu alat yang dapat mengkonversi radiasi matahari menjadi bentuk energi termal adalah kolektor surya. Intensitas radiasi matahari yang diterima kolektor surya tidak kontinyu tetapi fluktuasi karena adanya hambatan yaitu awan.

Untuk mengatasi fluktuasi intensitas radiasi maka pengambil panas haruslah responsif, agar panas yang datang dalam waktu singkat pun dapat diambil dari kolektor. Untuk itu digunakan pipa kalor yang dapat merespon dengan cepat adanya panas yang datang dalam waktu singkat. Penggunaan pipa kalor yang tepat dapat meningkatkan efektivitas kolektor, karena fluida pemindah panas dari pelat penyerap ke aliran pengambil panas bermassa kecil.

Tujuan dari penelitian ini adalah mengetahui kinerja sistem kolektor surya tipe pelat datar menggunakan pipa kalor sebagai pengambil panas dari absorber.

\section{Teori}

\section{Kolektor surya (solar collector)}

Alat ini berfungsi untuk menangkap energi panas dari radiasi matahari menggunakan pipa kalor dan memindahkannya ke fluida pembawa. Secara prinsip ada tiga tipe 
penyerap panas surya yang sering digunakan, yaitu : pelat datar (flat plate), evacuated-tube, dan concentrating.

\section{Kolektor surya tipe pelat datar}

Alat ini terdiri dari kotak tahan cuaca (wheaterproof) yang berisi pelat absorber berwarna gelap dibawah penutup transparan dari kaca. Sinar matahari menembus penutup transparan dan mengenai pelat yang berwarna gelap, sehingga temperatur pelat naik dan panas ini diserap oleh fluida yang berada di dalam pipa kalor. Tipe ini pada umumnya bekerja pada temperatur di bawah $90^{\circ} \mathrm{C}$.

Panas yang terserap oleh pelat diharapkan akan berpindah ke pipa, tetapi karena temperatur pelat yang lebih tinggi dari udara dalam kotak maka panas juga berpindah ke udara dengan cara konveksi. Secara umum temperatur sistem tinggi hingga mencapai $90^{\circ} \mathrm{C}$ dan udara disekitar kotak yang lebih rendah akan menerima panas dari kotak.

\section{Pipa kalor}

Pipa kalor yang ditempatkan pada dua daerah yaitu daerah panas dan daerah dingin, merupakan penghubung kedua daerah tersebut dengan konduktivitas termal yang sangat tinggi, mendekati material superkonduktor. Hal ini dapat terjadi karena perpindahan panas pada pipa kalor disertai dengan proses penguapan dan pengembunan fluida di dalamnya.

\section{Struktur Pipa Kalor}

Secara fisik pipa kalor terdiri dari pipa berongga yang tertutup pada kedua ujungnya, yang di dalamnya berisi sumbu dan fluida kerja, seperti ditunjukkan pada Gambar 1. Daerah atau region pipa kalor secara aksial umumnya terbagi tiga, yaitu bagian evaporator, bagian adiabatik, dan bagian kondenser.

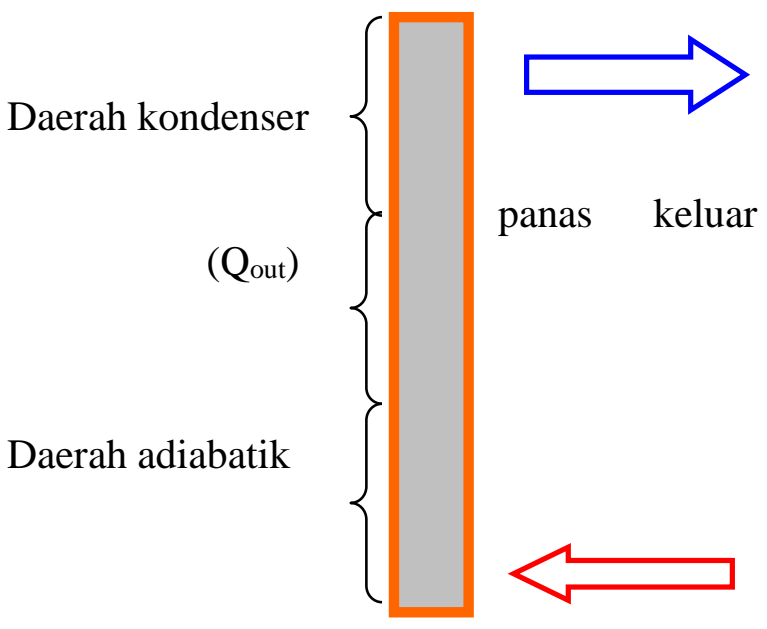

Daerah evaporator

panas masuk ( $\left.Q_{\text {in }}\right)$

Gambar 1. Sketsa pipa kalor.

\section{Peralatan}

\section{Kolektor surya}

kolektor surya yang digunakan tipe pelat datar dengan mengunakan pipa kalor, dengan rentang waktu operasi dari pukul 8.00 sampai 16.00. Rentang temperatur keluaran dari kolektor antara $40^{\circ} \mathrm{C}$ hingga $70^{\circ} \mathrm{C}$.

Dua unit kolektor yang masing-masing mempunyai permukaan penyerap panas 120 $\mathrm{cm}$ x $200 \mathrm{~cm}$. Tiap unit terdiri dari 20 pipa berjajar, dengan jarak antar pipa $10 \mathrm{~cm}$. Boks terbuat dari bahan alumunium tebal 1 $\mathrm{mm}$, bagian atas ditutup dengan kaca transparan setebal $5 \mathrm{~mm}$ dan bagian bawah diberi isolator termal berupa glasswool setebal $5 \mathrm{~cm}$. 
Kolektor dipasang miring $30^{\circ} \mathrm{C}$ menghadap ke arah utara, karena posisi geografis lokasi pengujian yang berada di $10^{\circ} \mathrm{LS}$.

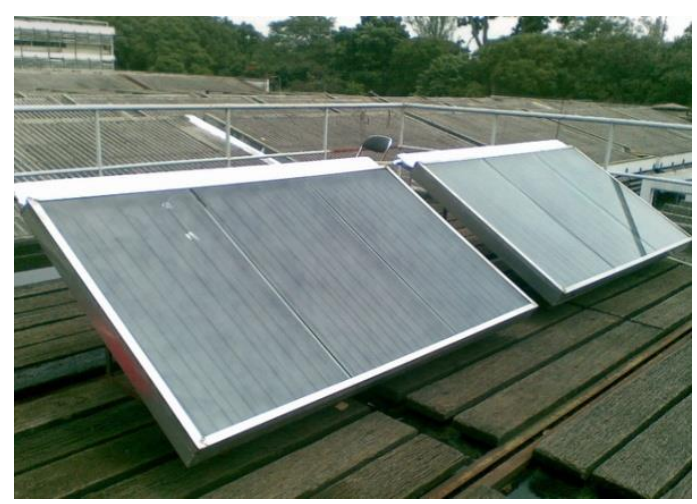

Gambar 3. Foto kolektor surya langsung. Pelat alumunium setebal $1 \mathrm{~mm}$ diwarnai hitam pekat digunakan sebagai penyerap panas matahari. Panas yang berhasil tertangkap oleh pelat ini berpindah ke pipa kalor yang direkatkan pada pelat sehingga berfungsi sebagai sirip bagi pipa kalor. Pelat yang digunakan berdimensi lebar $5 \mathrm{~cm}$ dan panjang sama dengan panjang daerah evaporator pipa kalor 118 $\mathrm{cm}$.

Bagian bawah pelat tidak diberi warna dan pelat diletakkan di atas isolator termal. Pewarnaan hitam pada pelat absorber bagian atas bermaksud untuk menangkap sebesar mungkin $(\alpha>0,8)$ untuk panjang gelombang matahari $(6000 \mathrm{~K})$ yang menembus kaca transparan $(0,3-1,8 \mu \mathrm{m})$.

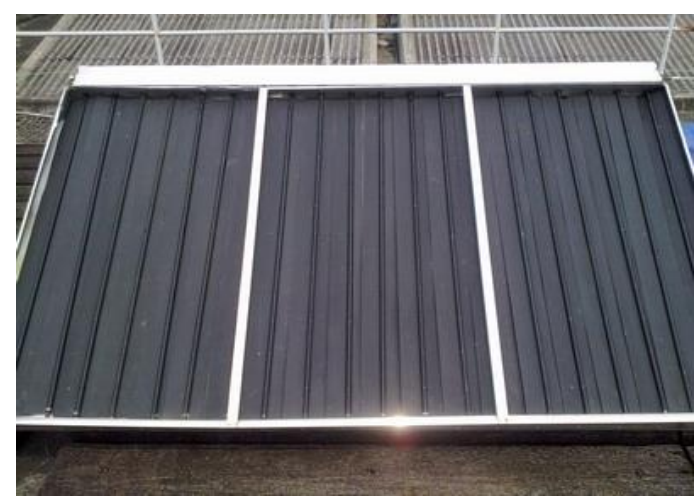

Gambar 5. Pipa kalor dan sirip.

\section{Penukar panas}

Panas yang berhasil diserap absorber dipindahkan oleh pipa kalor ke fluida pengambil panas di dalam saluran penukar panas. Saluran penukar panas mengambil panas dari pipa kalor yang berjajar, sehingga dimensi saluran dibuat sedekat mungkin dengan pipa agar panas efektif terambil. Saluran terbuat dari bahan alumunium 
berbentuk kotak dengan penampang melintang berukuran 25 x $100 \mathrm{~mm}$ dan panjang $2000 \mathrm{~mm}$. Permukaan luar saluran diberi isolasi, untuk mengurangi kerugian panas ke lingkungan dari saluran.

\section{Hasil Percobaan}

Pengujian awal kolektor dilakukan untuk mengetahui kinerja kolektor. Kolektor yang digunakan 2 unit dengan susunan awal seri, sehingga keluaran unit pertama menjadi masukan unit kedua. Input unit pertama bertemperatur rendah yaitu sekitar $25^{\circ} \mathrm{C}$. Hal ini dilakukan untuk mengetahui panas yang berhasil diambil oleh kolektor untuk masukan temperatur yang berbeda.

Pengujian kolektor dilakukan dengan cara pengukuran temperatur pelat absorber, air masuk, air keluar unit pertama (antara), dan air keluar, laju aliran air 0,004 kg/s.

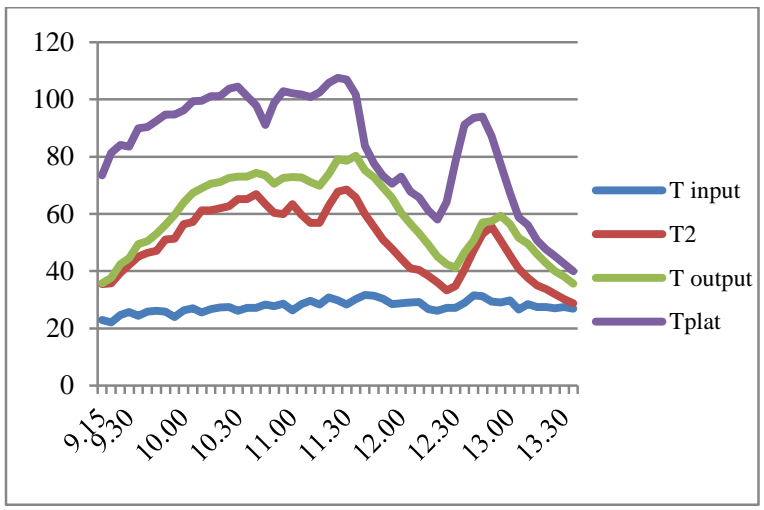

Gambar 7. Hasil pengukuran temperatur terhadap waktu hari pertama.

Hasil pengujian kolektor seperti ditunjukkan pada gambar 7,8, dan 10. Dari gambar effisiensi terlihat hasil yang masih kecil, terutama pada kolektor unit kedua. Hal ini karena masukan temperatur air yang relatif tinggi, sehingga beda temperatur dengan pelat absorber kecil.

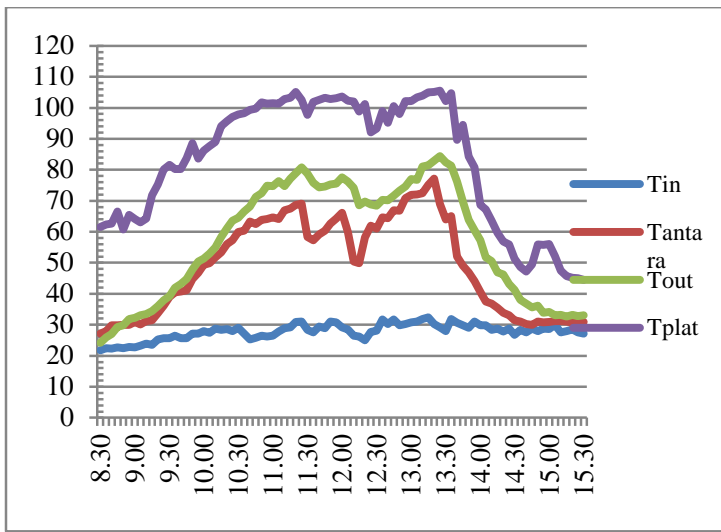

Gambar 8. Hasil pengukuran temperatur terhadap waktu hari kedua. Sinar matahari mulai terhalang awan mulai pukul 13.30.

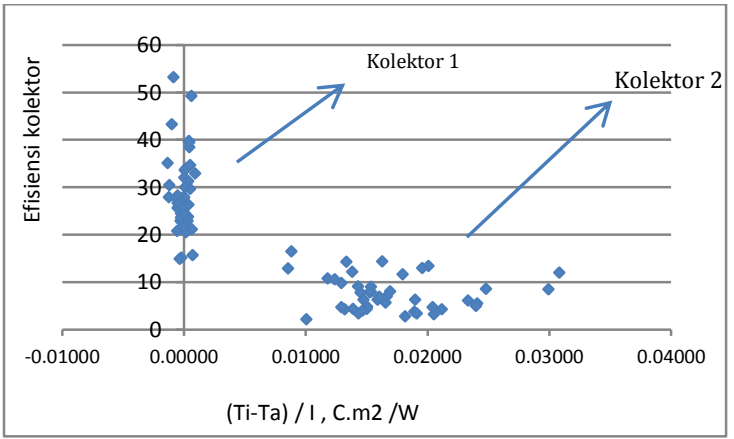

Gambar 9. Efisiensi kolektor.

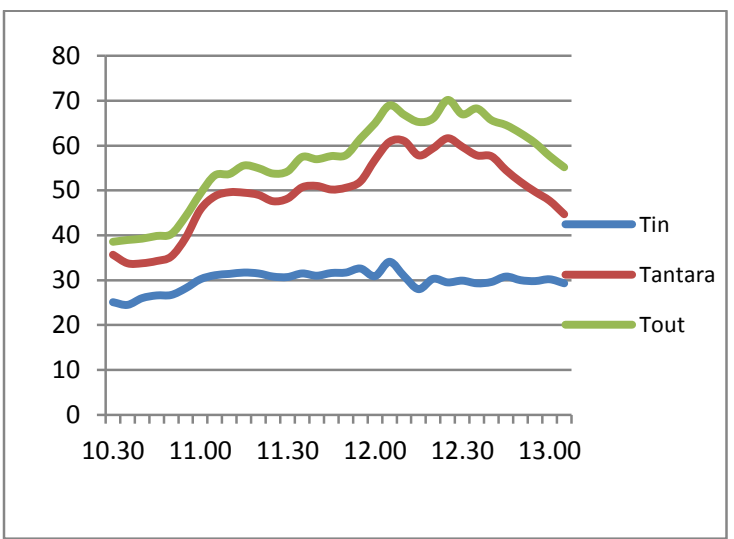

Gambar 10. Hasil pengukuran temperatur terhadap waktu hari ketiga. 


\section{Kesimpulan}

Kesimpulan dari pengujian awal penelitian ini adalah pipa kalor yang dipasang sebagai absorber radiasi matahari dapat bekerja dengan baik. Temperatur target minimal tercapai mulai pukul 10.00 . Efisiensi kolektor yang diperoleh kecil untuk masukan dengan temperatur tinggi.

Percobaan akan terus dilanjutkan untuk laju aliran air yang berbeda, sehingga akan diperoleh hasil yang optimal untuk laju aliran air.

\section{DAFTAR PUSTAKA}

1. Chi, S.W., (1976), Heat Pipe Theory and Practice, Hemispere Publising Corporation, Washington.

2. Collier, John Gordon. (1981), Convective Boiling and Condensation, Second Edition, McGraw-Hill Book Company, London.

3. Dunn, P., and Reay, D A, (1982), Heat Pipes, Third Edition, Pergamon Press, Oxford United Kingdom.

4. Engineering Science Data Unit, 80013, (1980), Heat Pipe General Information, London United Kingdom.

5. Facao, Jorge., Olivera, Armando C. (2004), Analysis of a Plate Heat Pipe Solar Collector, International Conference on Suitable Energy Teechnologies, Nottingham, UK June 2004.

6. Facao, Jorge., Olivera, Armando C. (2002), Simulatiom of Thermal Behaviour of a Hybrid Heat Pipe Solar
Collector, $1^{\text {st }}$ International Conference on Suitable Energy Teechnologies, Portugal

7. Hagens, H., Ganzevles, F.L.A., Van der Geld, C.W.M., Grooten, M.H.M. (2007) Air Heat Exchanger with Long Heat Pipe : Experiment and Prediction, Applied Thermal Engineering 27, 2426-2434.

8. Hewiit, G.F., Shires, Bott, (2000), Process HeatTransfer, Begell House Inc, New York USA.

9. Huang,B.J., Lee, J.P., Chyng,J.P. (2005), Heat Pipe Enhance Solae Assisted Heat Pump Water Heater, Solar Energy 78375 - 381.

10. Incropera, Frank P, and De Witt, David P., (1990), Introduction to Heat Transfer, Second Edition, John Wiley \& Sons, New York.

11. Legierski, Jarosław., Wiecek, Bogusław., de Mey, Gilbert. (2006), Measurements and simulations of transient characteristics of heat pipes, Microelectronics Reliability 46 109115.

12. Mathioulakis, Emmanouil., Bellessiotis, Vassilis, (2002), A New Heat Pipe Type Solar Domestic Hot Water System, Solar Energy 72 13-20.

13. Rittidech,S., Wannapakne, S. (2007), Experiment Study of the Performance of a Solar Collector by Closed-end Oscilating Heat Pipe, Applied Thermal Engineering 27 1978-1985.

14. Vasiliev, Leonard L. (2005), Heat pipes in modern heat exchangers, Applied Thermal Engineering 25 1-19 